\title{
Chinese Character Teaching and Learning with Marginalized Radicals and Non-radical Components in a Character
}

\author{
Bianye Li \\ George Brown College, Toronto, Canada
}

\begin{abstract}
Naming or indexing of a radical in a dictionary will foreground dominant meanings of a radical and, at the same time, marginalize the other meanings of a radical as well as the meanings of non-radical components in a character. More efforts should be made to go beyond the dominant meaning(s) of a radical to have a better knowledge of the marginalized meanings of a radical and to identify the meanings of non-radical components in a character. With the assistance of Oracle/Bone Script, Bronze Script, and Seal script, and reinstatement of the significance of the marginalized meaning(s) of radicals or non-radical components, the Chinese character teaching and learning process will be considerably improved and it will become a fungenerating experience.
\end{abstract}

Index Terms - Chinese character teaching and learning, dominant radicals, dominant meaning of a radical, meanings of marginalized radicals, meanings of marginalized non-radical components

\section{INTRODUCTION}

The Chinese character teaching and learning more often than not begins with strokes and radicals. Radicals play a crucial role in helping an adult learner learn Chinese as a second language. Naming or indexing of a radical in a dictionary will influence the visual attention and semantic understanding of an adult learner and foreground the dominant meaning of a radical, and at the same time marginalize the other meanings of the same radical. This kind of naming and indexing will sometimes exclude the secondary meanings of a radical or downplay the meanings of nonradical components in a Chinese character. The current state of Chinese character teaching and learning is mainly based on the dominant meanings of a radical or radicals. More efforts should be made to go beyond the dominant meaning(s) of a radical in order to have a better knowledge of the marginalized meanings of a radical and to identify the meanings of non-radical components in a character as well. Otherwise, the Chinese character teaching or learning will reach a plateau, and the meanings of many components in a character can only be partially understood, and as a result, Chinese character teaching and learning sometimes will become only a memory work of radicals and fail to become a fungenerating process which will stimulate and sustain adult learners' interest in learning Chinese characters. With the assistance of 甲骨文 Jiǎgǔwén 'Oracle/Bone Script', 金文 Jīn wén 'Bronze Script,' and 管文 Zhuànwén 'Seal script', and with reinstatement of the significance of the marginalized meaning(s) of a radical and a marginalized non-radical component in a character, the Chinese character teaching and learning process will be considerably improved and it will become a fun-generating experience.

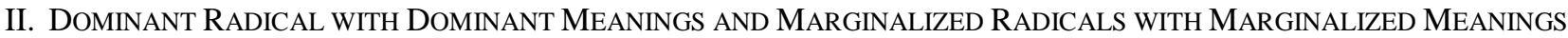

"Radical" here is an English term designated to mean both Chinese words 部首 bù shǒu and 偏旁 piānpáng, which are indexed in a Chinese dictionary and by which a reader can easily look up a word in a Chinese dictionary. Some radicals convey meanings, and some do not play a semantic role in a character. In most cases, one Chinese character in a Chinese dictionary has one and only one radical, under which many characters with the same radical are listed together for the convenience of being found in the dictionary.

In the history of the Chinese language, Chinese characters had undergone a drastic change, especially from 管文 zhuànwén 'Seal Script' to 隶书 lishū 'Official Script'. The change from Official Script to Seal Script is a change from picture-oriented or image-oriented scripts to completely stroke-oriented characters. A systematic formation of Chinese characters with only strokes is first realized in Official Script. Hieroglyphs, pictographs or images are no longer allowed to appear in the stroke-oriented Official Script. This change from Seal Script to Official Script or from image-oriented to stroke-oriented imposes two far-reaching effects on Chinese character teaching and learning:

1. Different pictures or images in Oracle/Bone Script, Bronze Script, and Seal Script will find their respective counterparts in different types of strokes or different components in Official Script. For example, different pictures or

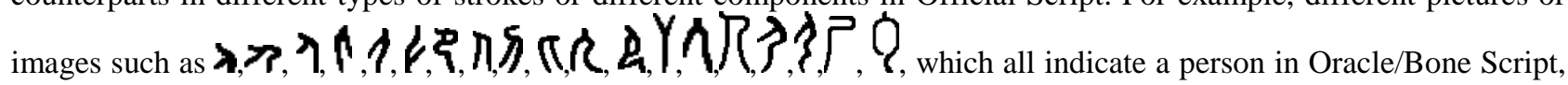
Bronze Script or Seal Script, have found their equivalents in strokes, radicals or components such as 人, 亿, 人, リ, 万, 七, 
儿, ケ, ア, 尸, 巴, etc. Some of the radicals representing a person are quite recognizable, and easy for a learner to remember such as 人, イ, 人, due to their special listing as a radical in a dictionary and due to their nature of recognisability. Therefore, I refer to radicals of this kind as "dominant radicals" which is a dominant indicator for a

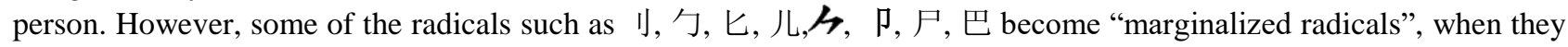
are not or less or least expected to represent a person, or they are not a dominant indicator for a person. The marginalized radicals present a challenge for Chinese character teaching and learning because they have become less recognizable or unrecognizable and more obscure over time. Therefore, I refer to radicals of this kind as marginalized radicals with marginalized meanings.

2. The change from picture-oriented or image-oriented in Seal Scripts to stroke-oriented in Official Script is so drastic that many different pictures or images with different meanings are totally scarified in order to be transformed into the same radicals or the same components in characters and to serve the purpose of simplicity and reduce the number of different types of radicals. The pictures or images, originally different in shape and meaning, have to share the same radicals or components now. Therefore, many changes are often considered by the author of 象形字典 xiàngxing zìdiăn 'Dictionary of pictographs' (vividict.com, 2020) as mistakes. Take the radical 四点底... Sì diăn dì 'four-dot bottom component' for example. It is often used to indicate 火 huó 'fire' as in the Chinese characters 热 rè 'hot', 照 zhào 'illuminate', 蒸 zhēng 'steaming', etc. Therefore, 四点底 ... as an indicator for 火 huǒ becomes the dominant meaning of this radical. However, this same bottom component is also used to indicate 鸟爪 niăozhăo 'birds claw', 鸟羽 Niǎoyǔ 'bird feathers', 鸟尾 niăowěi 'bird tail', 鱼尾 yúwěi 'fish tail', 马蹄 mătí 'horseshoes'. (See

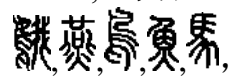
is graphically similar but etymologically unrelated to the usage of the same 'four-dot bottom component' to indicate $火$ huó 'fire.' Actually, it turns out not as a kind of mistake as indicated. This application is designed for the sake of simplicity in order to reduce the number of different kinds of strokes or to avoid creating another new type of radical. As a result, one radical might indicate many different meanings in different characters. However, some meanings of a radical become dominant or overemphasized in our teaching; at the same time, some other meanings of the same radical are marginalized or neglected, and even fail to be identified in our teaching. More often than not, fun will be lost in our teaching or learning if the marginalized meanings of a radical in a character fail to be identified. For example, 月 yиè, whether as a radical or as a non-radical component of a character, is often referred to as either "Moon" or "Meat" in our teaching or learning. "Moon" or "Meat" becomes a dominant meaning for the radical 月 yuè. Actually, the radical 月 carries many other meanings other than just "Moon" or "Meat." For example, $\boldsymbol{D}$ in $\stackrel{\boldsymbol{*}}{\boldsymbol{D}}$ (Oracle/Bone Script) indicates a

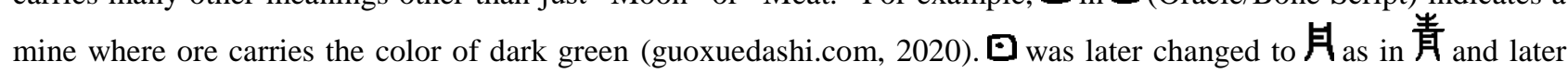
changed to 月 as in 青 qing. Here “月” has nothing to do with "Moon" or “Meat." Another example of transformation

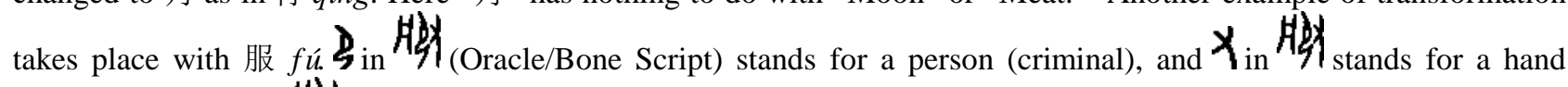

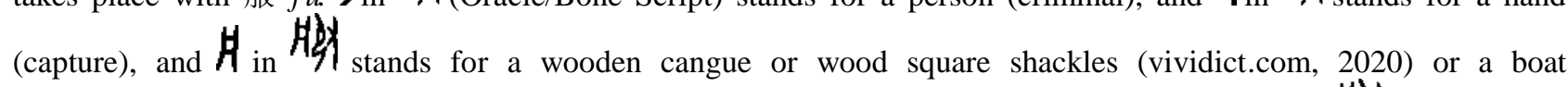

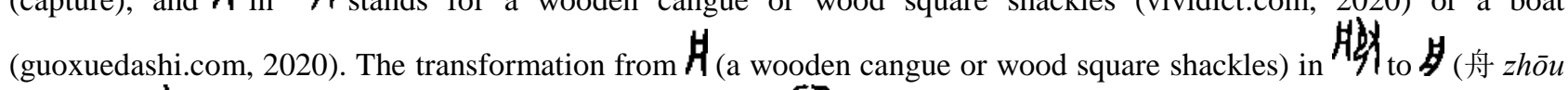

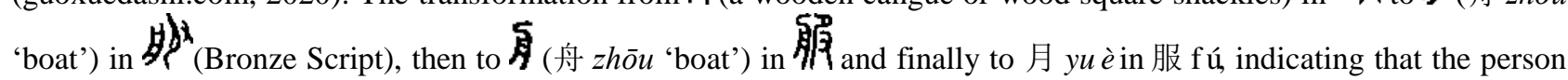
was captured and forced to wear a wooden cangue or wood square shackles (vividict.com, 2020). This change is considered also as an erroneous transformation both in vividict.com and chaziwang.com. However, even though this transformation is referred to as erroneous, it is carried out consistently on purpose to avoid creating a new radical or

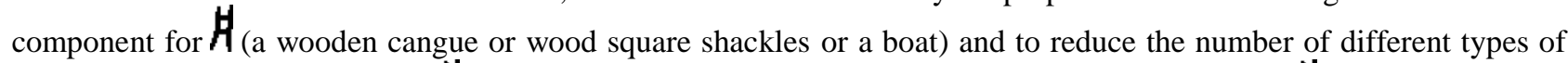
radicals. This transformation of (舟 zhōu, boat) into 月 yuè does not happen only in 服 fú, and (舟 zhōu 'boat') is transformed into 月 yuè also in 愈 $y u ̀$. (舟 $z h \bar{o} u$ 'boat') in

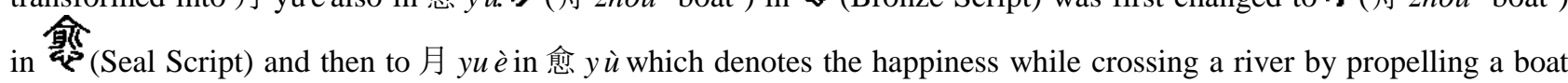
with a long pole (jiagumima.com, 2020 and vividict.com, 2020); another transformation of the same kind is found in sol

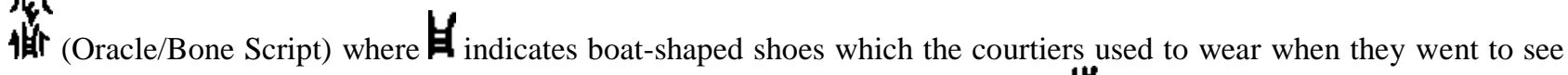

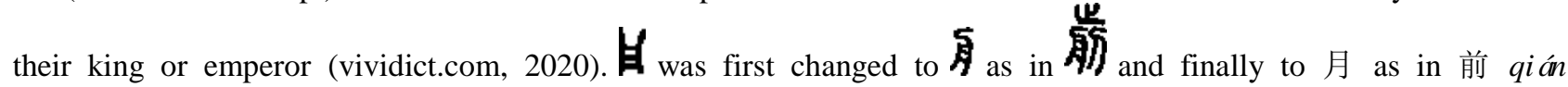
(vividict.com, 2020 and guoxuedashi.com, 2020). If the marginalized meanings of 月 as "Boat" can be identified, it not only can help us have a better understanding of the meanings of these characters, but also we can generate more fun from the marginalized meanings of a radical rather than only from the dominant meanings of a radical in our Chinese character teaching and learning. As another example, the radical 月 is found in the word 朕 zhèn. The radical 月 in 朕 
has nothing to do with the dominant meaning of either "Moon" or "Meat." Nowadays, 朕 zhèn is simply a word used by an emperor to call himself. However, 朕 zhèn was first illustrated in Oracle/Bone Script as (vividict.com, 2020 and guoxuedashi.com, 2020), \(a helm, vividivt.com, 2020) or \(a rod to caulk the seams of a

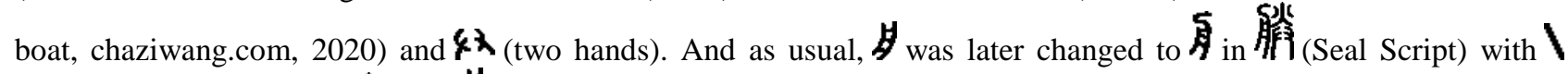
(helm or rod) changed to $火$, and was finally changed to 月 in 朕 zhèn, carrying the meaning of being a helmsman (vividict.com, 2020). If this meaning of being a helmsman were reliable, then it would remind us of Cultural Revolution when "Four Greatnesses - Great Teacher, Great Leader, Great Supreme Commander, Great Helmsman" became so popular nationwide in China. If we knew 朕 was originated from being a helmsman, we might have a different understanding why Great Helmsman was chosen instead of "Great Driver or Pilot" in Cultural Revolution. As a result, an association, whether intentional or unintentional, whether erroneously or fittingly, would be made between 舵手 Duòshǒu 'helmsman' and 朕 or between 舵手 Duòshǒu 'helmsman' and 皇帝 huángdì 'emperor.' Here, this marginalized meaning of as a "Boat" turns out to be much more fun than we expected.

Therefore, Chinese character teaching and learning sometimes should go beyond the dominant radicals and the dominant meaning of a radical so that it can reach for the marginalized radicals and the marginalized meanings of a radical. For example, 立 $l \grave{l}$ as a radical is defined as "Standing" by Arch Chinese (archchinese.com/chinese_radical_stroke_count.html, 2020) and Read and Write Chinese (Choy, 1990, p. 33). As a radical, it is called 立字旁 lì zì páng, under which all the characters which are said to bear the standard radical name 立 lì are listed together in a dictionary. However, about half of these characters with 立 lì have nothing to do with "Standing." Only the characters with the radical 立 li constituting the left part of these characters are related to "Standing." A large number of characters with 立 lì are related to 辛 xīn instead, especially with 立 lì constituting the top part of a character. However, the meaning of 辛 $x \overline{i n}$ in the characters listed under this radical 立 lì is marginalized by naming itself in a dictionary or by naming the radical 立 lì only as "standing." When we come to a Chinese character with the meaning of “辛” xīn instead of "standing," we might give it up in our character teaching or learning because it has nothing to do with "standing." Therefore, it is not a radical itself which marginalizes the other meanings of a radical, but it is the naming of a radical that excludes the other meanings of the radical “立" lì. If we are still satisfied with the dominant meaning of a radical and refuse to de-marginalize the other meanings of a radical, our Chinese character teaching will not release any further information about the marginalized meaning of a radical and will not lead to a significant improvement in our character teaching to satisfy the needs and curiosity of an adult learner of Chinese as a second language. Consequently, the interest and curiosity of an adult learner will be short-lived. Therefore, the other meanings of a radical should be de-marginalized and our Chinese character teaching should be empowered with some knowledge about Oracle/Bone Script, Bronze Script and Seal Script. With the assistance of Oracle/Bone Script, Bronze Script and Seal Script, it is more likely that the meaning of a component in a character can be more fully or completely captured. For example, 立 lì can be traced back to $\bar{\Psi}$ or $\overline{\bar{Y}}$ in Oracle/Bone Script. $\bar{\Psi}$ or $\overline{\boldsymbol{F}}$ (Oracle/Bone Script) consists

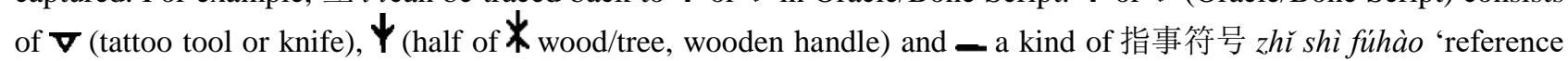
stroke' denoting the action of tattooing or implement of punishment by a torture dagger (chaziwang.com, 2020). Therefore, 辛 $x \bar{\imath}$ n or even 立 $l i$ is related to the criminals who were often marked with face tattoos and exiled for their

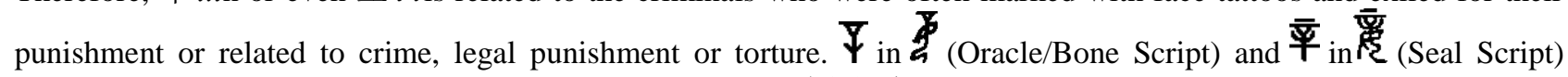
mean a punished female slave (jiagumima.com, 2020 and 说文解字 Shuō wén jiě zi Shuo Wen Jie Zi) from where the meaning of 妾 Qiè 'concubine' was later developed. $\overline{\mathbf{Y}}$ in $\overline{7}$ (Bronze Script) and 剩 (Seal Script) denotes “visiting a family member in a prison." (vividict.com, 2020). Later, 魏 is changed to the simplified Chinese character 亲 qin with 见 jiàn omitted. $\mathbf{Y}$ in (Oracle/Bone) means a knife which was used to make a young slave's eyes blind so that he

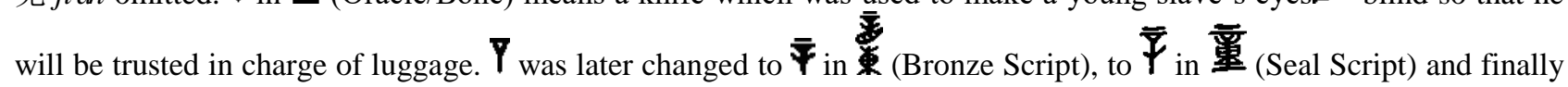
to 立 lì in 童 tóng (vividict.com and baike.baidu.com). Many characters with 立 lì as their component are even not included under the radical 立 lì. They carry the meaning of crime, legal punishment or torture as in 宰 zăi, 辟 pì, 辩 biàn, 辨 biàn, 商 shāng, 辞 cí, 撞 zhuàng, etc.

More examples of marginalized meanings of a radical are found in “父” or “タ”. $\mathbf{P}$ or $\boldsymbol{4}$ is listed under a radical indicating 刀 dāo 'knife' in a dictionary (Radicals Guide, P. 42, The Contemporary Chinese Dictionary, 2002). There is a controversial issue in (Seal Script, 色 sè 'color'). The author in chaziwang.com (2020) indicates that in (Oracle/Bone Script) or in (Seal Script) is a knife which signifies a severance. Furthermore, as the Chinese saying 
goes, “色字头上一把刀” sè zì tóu shàng yì bă dāo (“Indulging on your lust is equivalent to hanging a knife over your head'). A seemingly more convincing example in support of 7 as a knife in The meaning of $\overline{⿱ 丶 万}_{\text {in }}$ 舒 (Seal Script, 绝 jué) is semantically and graphically understandable. The meaning of knife “” in 8 (绝 jué, 'cutting off') is only roughly sketched in Seal Script. “一” serves as an indicative sign to convey the idea that the thread is cut into two fragments; $\mathcal{J}_{\text {in }}$ (Bronze Script) tries to "paraphrase" the meaning of - in

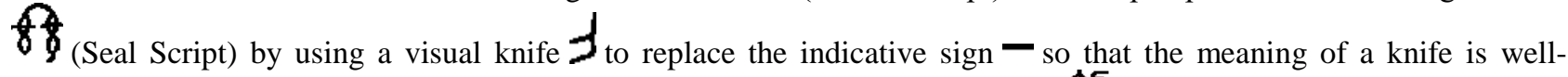
illustrated and not susceptible of any ambiguity; later, $\mathcal{W}_{\text {was replaced by }}$ as in

All the above factors - the naming of the radical $\zeta$ as a knife in a dictionary, the Chinese saying about the character 色 sè (“色字头上一把刀” sè zì tóu shàng yì bă dāo) and the visual illustration of the character 绝 jué in to the conclusion that $々$ in 色 sè denotes a knife. However, it seems to me still too early to make such a judgement that > in (Seal Script, 色 sè) is a knife, only because 々 is named as a radical to indicate a knife as a dominant meaning in a dictionary and the word 色 sè constitutes the right part of the word 绝 jué. An interesting example of 则 zé and 侧 cè will tell you a different story. Both of the authors in vividict.com (2020) and in chaziwang.com (2020) agree that

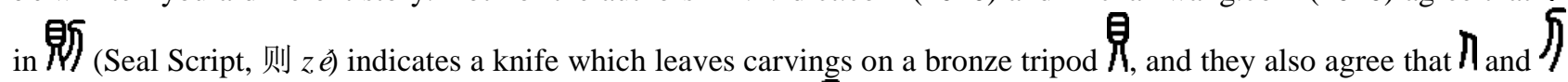
in $川$ (Seal Script, 侧 cè) indicates that two people $\left(\Pi_{\text {and }}\right.$ ) stand by each side of a bronze tripod $\boldsymbol{\lambda}_{\text {. Therefore, }}$

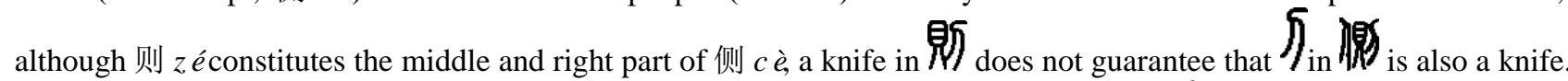
A further study will reveal that almost a half of the listed characters under this radical $\zeta$ have nothing to do with a knife. It turns out that some of them indicate a person instead, especially when $\zeta$ constitutes the top part of a character.

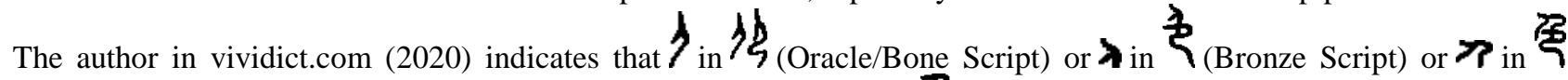
(Seal Script) is the person who positions himself over another person $\mathcal{Z}_{\text {when engaged in a sexual activity. It seems to }}$ me that the character 色 sè itself was related first to or more to sexual desire, lust or lechery as in the phrase 好色 hàosè and was only later developed to indicate "Color." Therefore, $\boldsymbol{\nearrow}$ as a radical for a person has been marginalized, mainly due to the exclusive way of naming this radical as a knife. Naming of a radical will influence visual attention and semantic understanding in our Chinese character teaching and learning. The naming of a radical will foreground the dominant meaning of a radical and at the same time marginalize the other meanings of the same radical.

More examples of $\boldsymbol{\zeta}$ as a person can be found in the following: $\boldsymbol{>}$ in

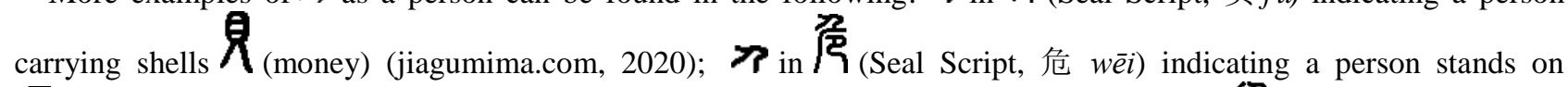
$\Gamma$ (cliff) and exposes himself to a risk of falling off a cliff (guoxuedashi.com, 2020); 7 in 粫 (Seal Script, 换 huàn)

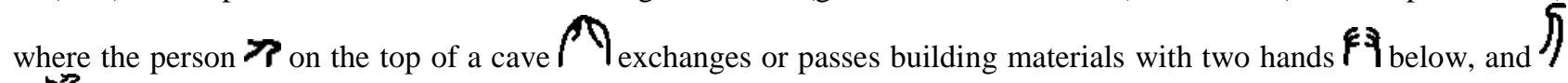
in 膽(Seal Script, 擔/担 $d \bar{a} n$ ) where a guard $\boldsymbol{\nabla}$ on duty is standing on the top of a cave and tries to provide an early warning to others (vividict.com, 2020).

Some radicals are really well-named for the sake of convenience. There are three well-known "ears" listed as radicals in a dictionary: 队 (左耳旁 zuǒ ér páng), 队 (右耳旁 yòu ér páng) and 『 (单耳旁 dān ér páng) are respectively called "left ear", "right ear", and "single ear." Pinyin for 卫 (单耳旁 dān ěr páng) is jié, carrying the same sound as 节 jié. P as a radical is defined as "seal" by Arch Chinese (2020), and Read and Write Chinese (Choy, 1990, p. 31). P is called “单耳刀 Dān ér dāo" or “单耳旁 dān ěr páng” in wanmeila.com (2020). The above naming of these three ears is so visual and vivid that they are among the easiest radicals for kids to remember. However, they are very misleading to adult learners because these radicals have nothing to do with ears at all. 队 (左耳旁 zuǒ ěr páng) indicates a hill, a mountain, a cliff or stone steps winding up a mountain; 阝 (右耳旁 yòu ěr páng) indicates a village, a town or a city. However, the third ear $卩$ denotes a person, more often in a kneeling position. For example, $h_{\text {in }}$ (Oracle/Bone

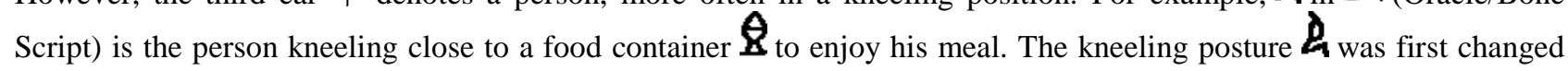




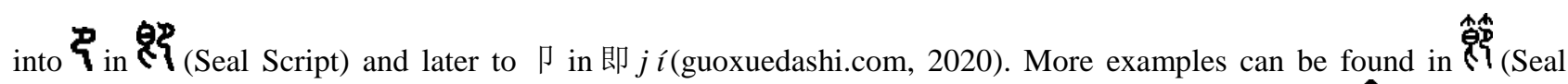

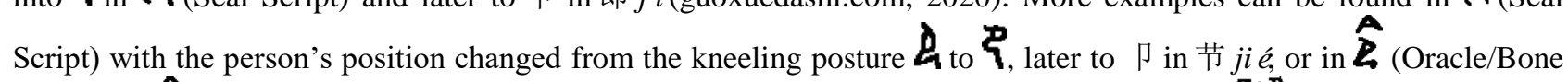
Script), in (Seal Script) and 命 ming, with the person kneeling to receive an order; or in 484 (Oracle/Bone Script)

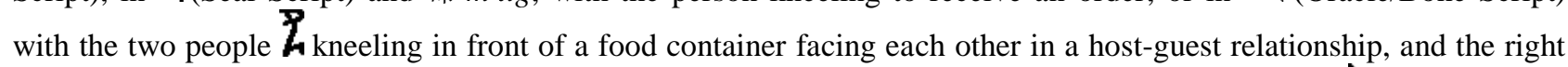
person was later changed into $\boldsymbol{P}_{\text {in }}$ 郷 (Official Script) and $\mathrm{P}$ in 卿 qing (guoxuedashi.com, 2020). 4 (Oracle/Bone Script, 印 yìn) consists of a kneeling person 1 and hand (capture). The whole character 印 yin, instead of only representing a kneeling person 1 , indicates that a kneeling criminal receives a brand on his forehead before being dispelled to a remote area. Therefore, $\Gamma$ in this character indicates only a person in a kneeling position instead of the whole meaning of the character 印 yìn as a seal. Naming of the radical ए as "single ear" or "knife" or "seal" is not only misleading, but also marginalize the real meaning or other meaning of ए. When ए as a radical is defined as a "seal" both in archinese.com (2020) and in Read and Write Chinese (Choy, 1990, p. 31), this definition has marginalized the major meaning of the radical $\mathrm{P}$ as an indicator for a person or a person in a kneeling position and used the meaning of the character 印 yin instead to substitute the meaning of its radical p as a person.

尸 $s h \bar{\imath}$ as a character is always referred as "Corpse" when being translated from Chinese into English. Рshī as a radical is defined as "Corpse" in archchinese.com (2020). However, 尸 shi is also referred to as "a person (in ancient times) who sat behind the altar, acting as the deceased during the performance of sacrificial rites” (汉英词典 hàn ying cídiăn, A Chinese-English dictionary (1999). The naming of Р shī as "Corpse" has marginalized the meaning of as a living person in a sitting position. It turns out that only a few Chinese characters listed under the radical P sh $\bar{l}$ indicates "Corpse." If 尸 shi serves as a radical, it denotes, on most occasions, a living person instead of a dead person, especially relating to the buttock and private parts of a living person or relating to the sitting position of a living person. For example, $\}_{\text {in }} \gamma_{\text {(Oracle/Bone Script) and }} \overbrace{\text { in }}$ (Seal Script, 尾 wěi 'perineum or tail') both mean a person with

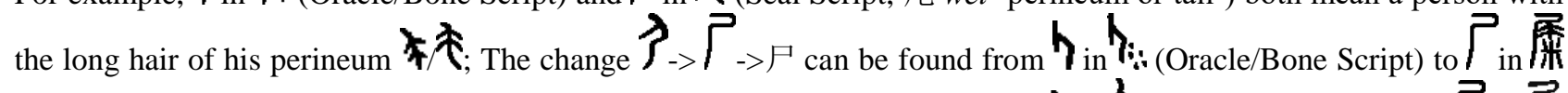

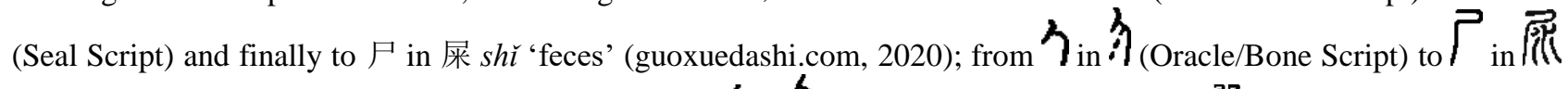
(Seal Script) and finally to P in 尿 niào 'urine'; from $\boldsymbol{\gamma}_{\text {in }} \boldsymbol{P}_{\text {(Oracle/Bone Script) to }} \boldsymbol{\Gamma}$ in 殿 (Seal Script) and finally to Р in 臀 tún 'buttocks'(guoxuedashi.com, 2020). The meaning of P as a living person in a sitting position has been marginalized due to the naming of this radical P as "corpse" in a dictionary and should be reinstated in our character teaching and learning.

万 as a radical is another example of marginalization by naming ' as "wrapping" in archchinese.com (2020) and Read and Write Chinese (Choy, 1990, p. 31). Unfortunately, ' as an indicator for a person in a bending position has not been sufficiently stated in our character teaching and learning. Its semantic connection between the meaning of a person in a bending position and its indicator ' has been marginalized. If a person is bending forward, he will adopt a

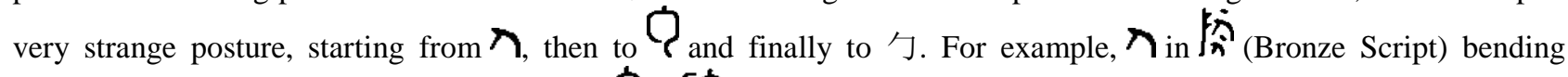
forward in making pottery is transformed into in (Seal Script) and adopts its final version 万 as a person in 陶 táo (guoxuedashi.com, 2020); the same change happens with 甸 where the person $\left.\hat{\chi}_{\text {in }} \oplus\right\}_{\text {(Bronze Script) is ploughing in }}$ the field $\boldsymbol{\Theta}$ with his body bending forward, and $\boldsymbol{\eta}_{\text {is changed first to }}$ in (Seal Script), and finally to diàn (jiagumima.com, 2020). More examples are found in 富(Seal Script, 匐 fú) (jiagumima.com, 2020), and in 第

Chinese character teaching or learning sometimes should not only go beyond the dominant radicals in order to reach for the marginalized meanings of a radical, but it should also go beyond radicals themselves so that the non-radical components in a character will deserve enough attention for their marginalized meanings.

\section{NON-RADICAL COMPONENTS IN A CHARACTER}


As I mentioned above, in most cases, a Chinese character in a Chinese dictionary has one and only one radical, (It is interesting to find that 合 hé has two different radicals indexed in one dictionary: one is 人 rén and the other is 口 kóu. Therefore, you can look for 合 hé under either the radical 人 rén or the radical 口 kóu (Contemporary Chinese Dictionary, 2002). If “口” in 合 hé is considered as a radical in a dictionary, I will refer to the remaining component “А” in this character as "non-radical component" because "А" is not indexed as a radical under this listing. If 人 rén in 合 hé is considered as a radical in a dictionary, I will refer to “一 + 口" as "non-radical component" in this character because the combination of “一 $+\square$ " is not indexed as a radical. The non-radical components can be further divided into two categories:

1. Some non-radical components such as 马 $m \check{a}$ in 妈 $m \bar{a}$ have the potential of being a radical in another character such as in 骑 qí;

2. Some non-radical components in a character are least likely to be or never have been used as radicals such as $\triangle$ in 合 hé, 丸 wán in 执 zhí, 凡 fán in 恐 kǒng,

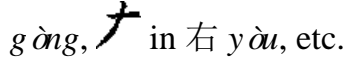

The focus of my study here is centered on the second category, (hereafter the term "non-radical components" are only referred to the second category). In the second category, the non-radical components can be further divided into four types.

\section{FIRST TYPE OF NON-RADICAL COMPONENTS}

The first type of a non-radical component comes into being when this non-radical component, originally as a meaningful entity, has been deconstructed, and part of this non-radical component has been chosen as a radical in a dictionary. It is not a radical itself that plays a role of marginalization. But it is "choice making" itself that will deconstruct the components in that character and make the meaning of that non-radical component inaccessible to an adult learner.

$\triangle$ in 合 hé is a non-radical component of the first type. $A$ has never been indexed as a radical in a dictionary. Although both “人” rén and “口” kǒu in 合 hé have been indexed as a radical in one dictionary, neither the radical 人 rén nor the radical $\square$ kǒu, nor a combination of 人 rén and $\square$ kǒu can thoroughly and completely explain the meaning of 合 hé. 人 rén is chosen as a radical by taking apart $\triangle$ as two separate parts --- “人” and “一.” As a result, the holistic meaning of $A$ is lost, and the whole meaning of the character 合 hé becomes insusceptible of being decoded due to the lack of the explanation of the component "一” in 合 hé. Here, the meaning and function of $\triangle$ are marginalized when “人” in 合 hé is considered as a radical and when $\triangle$ is taken apart as two separate parts ---- “人” and"一” in a dictionary. If any learning or teaching methods are built only on the radical 人 rén in this character as a proxy for semantic annotation, a complete explanation of the meaning of 合 hé becomes infeasible. Actually, $\boldsymbol{A}$ as a combination of “人” and “一” should be considered as one single indivisible non-radical component which plays an important role in helping us comprehend the structure of this character and the whole meaning of 合 hé. $\triangle$ in 合 hé indicates a mouth facing downward to kiss another mouth $\mathbf{U}$ (口 kǒu) facing upward (vividic.com, 2020). Or, А in 合 hé indicates "lid" facing downward to cover the hollow container which is open upward (guoxuedashi.com, 2020). Therefore, the understanding of the meaning of the radical “人” rén and “口” kǒu in 合 hé will not suffice without the knowledge of

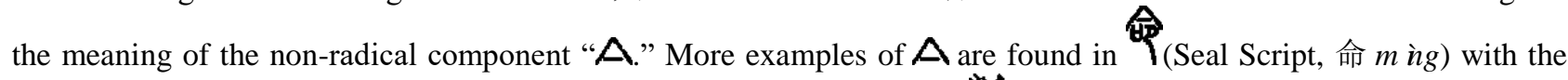

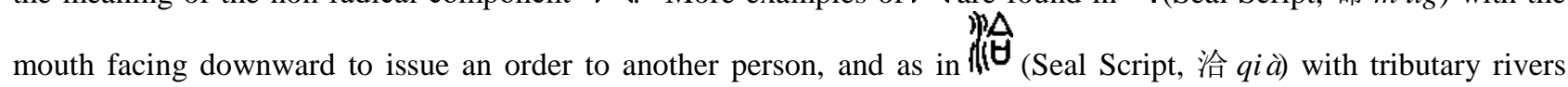
converged just as two mouths kissing each other or a lid to cover an open container.

$\pi$ in 共 gòng is another non-radical component of the first type in a character. $\pi$ has never been indexed as a radical in a dictionary. When “八” is indexed in a dictionary (Contemporary Chinese Dictionary, 2002) as a radical for 共 gòng, $\boldsymbol{T}$ is taken apart as two separate parts --- “一” and “八” bā. “八” indicates “division” in Oracle/Bone Script and is defined as "eight" by Arch Chinese (archchinese.com/chinese_radical_stroke_count.html, 2020) and Read and Write Chinese (Choy, 1990). When “八” $b \bar{a}$ is chosen as a radical for 共 gòng, the holistic meaning of $\pi$ as “two hands" is lost, and a complete explanation of the character 共 gòng will be denied its access due to the lack of the explanation of the component “一” in 共 gòng. Here, the meaning and function of $\pi$ are marginalized when $\pi$ is deconstructed as two separate parts ---- “一” and “八.” If any learning or teaching methods are built only on the radical “八” in this character as a proxy for semantic annotation, a satisfactory explanation of the meaning of 共 gòng will not be obtained. Actually, $\pi$ as a combination of “一” and “八” should be considered as one single indivisible non-

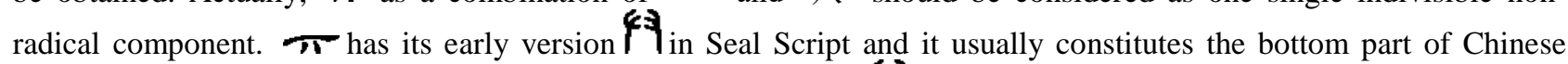
characters. When it constitutes the bottom part of a character, $\mathbf{F}$ will undergo a change to $\pi$ in some of these 
characters. For example, $\mathbf{F}_{\text {in }} \mathbf{4}$ (Seal Script) was finally changed to $\pi$ in 共 gòng with hands holding sacrifices to a

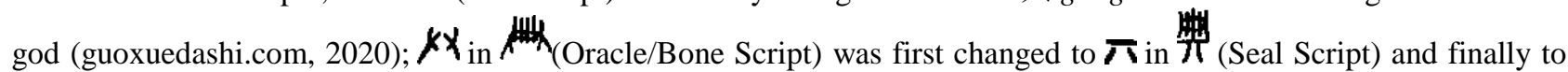
$\pi$ in 典 diăn with two hands holding ancient/classic books for reference. More examples are found in 兵 bing, 兴 xīng, 供 gōng, etc.

On most occations, when $\mathbf{F}$ (two hands) in Seal Script constitutes the bottom part of a character, it might be transformed later into either $\boldsymbol{\pi}$ or $\boldsymbol{\pi}$. Unlike the radical 井, $\boldsymbol{\pi}$ is a non-radical component which has never been listed as a radical in a dictionary. Therefore, the meaning of $\pi$ as "two hands" should be de-marginalized, and $\pi$ as a non-radical component should be reinstated to its well-deserved place as significant as the radical 井 in our teaching or learning.

\section{SECOND TYPE OF NON-RADICAL COMPONENTS}

The second type of a non-radical component comes into being when some elements of this non-radical component are denied their own independent existence in a character. These elements might have their own independent existence before, but when they are combined with another component to form a new non-radical component, this combination will deny their respective independent existence.

For example, the "two hands 4 " has its own independent existence in a character. When it is situated in the middle of a character, it will combine itself with the top component in a character and then transform this combination into something more or less like米 or 奏. Whether夹 or 米 and 奏 themselves never have an independent existence as a character or as a radical in a character other than being a non-radical component in a character.

The "two hands 4 " has its own independent existence in (Seal Script, 卷 juăn), and it was later combined with the top part 米 $m \check{\imath}$ 'rice' and then transformed into 米. 米 indicates the two hands rolling up the (cooked) rice into a rice ball or wrapping up cooked rice. 49 has its own independent existence in 毱 (Seal Script, 䅈 huàn), and it is later combined with the top part 米 to indicate rolling up some food to feed a pig (guoxuedashi.com, 2020). The character 䅈 huàn is listed under the radical 豕 shı̀ in a dictionary instead of 米. 豕 shì is defined as "hog." However, the understanding of the meaning of the radical 豕 shı̌ in 䅈 huàn will not suffice without the knowledge of the meaning of the non-radical component “兴." Our teaching experience tells us that we more often than not are satisfied with the meaning of the radical 豕 shi without further pursuing the meaning of “夾”" because “龹”, is considered as deviant and too complicated to explain. Therefore, this type of non-radical components is marginalized and even ignored in our Chinese character teaching and learning.

When $49_{\text {in }}$ 䊤 (Seal Script, 拳 quán) is combined with the top part 米, it will be changed to “头”, to indicate

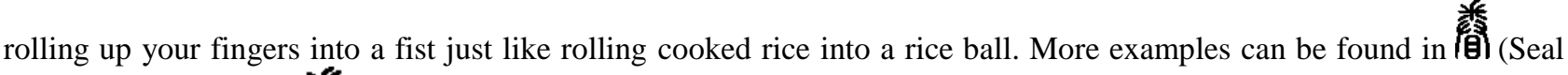
Script, 眷 juàn) and in (Seal Script, 券 quàn).

奉 itself never has an independent existence other than being a non-radical component in a character. It more often is engaged in a two-hand involved activity with an exception of the character 春 chūn. In Bronze Script, 4 in

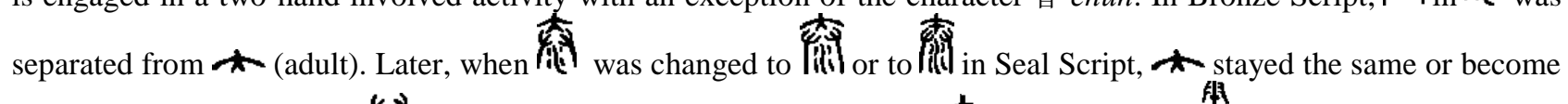

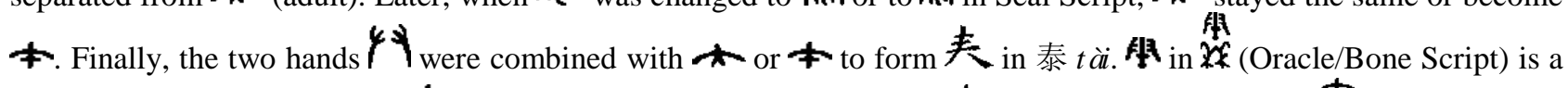

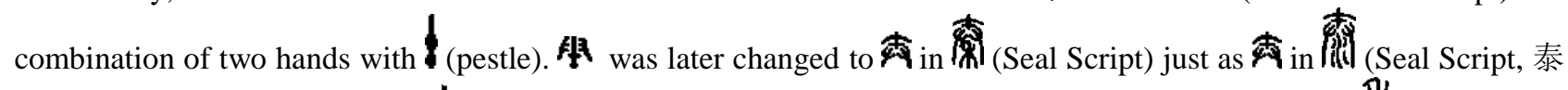
tài). 䨋 was finally changed to 㬰in both 秦 qín (with two hands holding a pestle to thresh grain $\mathbb{W}$ ) and 泰 tài (with the two hands washing his body with water $\mathbb{f ( l )}$. More examples can be found in 粚 (Seal Script, 奉 fèng with

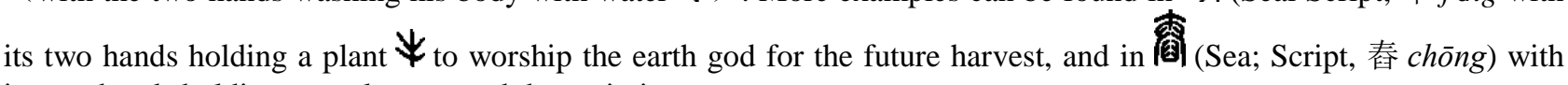
its two hands holding a pestle to pound the grain in a mortar. 
The lack of their respective independent existence and the forced combination of two hands with an object make 龹 and lose their qualification of being candidates for a radical in a dictionary. Therefore, both 米 and 実 have been marginalized in our Chinese character teaching and learning, and their meanings become obscure over time.

Different from ${ }^{2}$, which is listed as a radical in archchinese.com (2020), + 胥 indexed as a radical in a dictionary. here means "meat", and means "hand." Both of them have their respective independent existence in a character. But the combination of $\boldsymbol{7}_{\text {has denied either }} \boldsymbol{7}_{\text {its respective independent }}$ existence in this character. They are considered as an inseparable entity just as 氶. The character 祭 is listed under the radical 示 shì which is referred to as "show" (Liu, 2009, p. 14). If we have a good knowledge of the meaning of 示 shì, your curiosity will probably drive you to seek for the meaning of the non-radical component $+7_{\text {in }}$ 糸. Otherwise, the curiosity and passion of an adult learner for the meanings of a Chinese character will not sustain for long.

The combination $\left(+\frac{7}{\text { ) }}\right.$ ) here means that the hand is holding meat. Therefore, 糸 (Seal Script, 祭 ji) indicates that the meat of an animal or human being is sacrificed as an offering to a god (guoxuedashi.com, 2020). More examples can be found in 囱 (Seal Script, 察 chá) with its indication to identify any miracles displayed in worship (qiyuan.chaziwang.com, 2020); in 蔡 cài, indicating that a straw-made person is sacrificed instead of a human being in the worship of offering meat to a god (guoxuedashi.com, 2020); in 擦 cā, with its indication to identify dirty spots in cleaning instead of carefully to identify any miracles displayed in worship.

Different from the combination $\left(\boldsymbol{\$}_{+}\right)$with its hand holding only meat, $\boldsymbol{\Xi}_{\text {denotes a hand holding anything else }}$ when it combines itself with one or two items which $\boldsymbol{\nexists}$ grasps. If it grasps one or two items, it will be denied its own independent existence in a character. As a result, it will retain its joint existence in a character only by grasping either one or two items. When it holds one item, it will obtain its existence as a radical or as a non-radical component in a

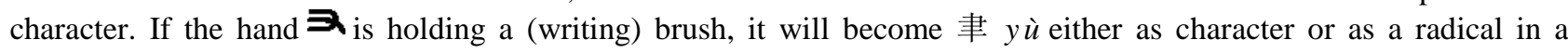
character. 聿 yù is indexed as a radical and defined by archchinese.com (2020) as an indicator for a "brush" and defined

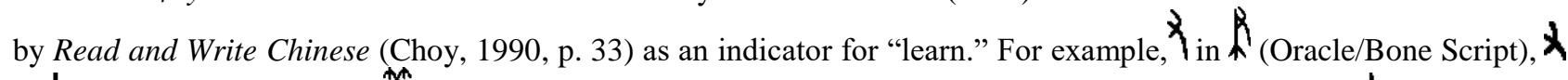

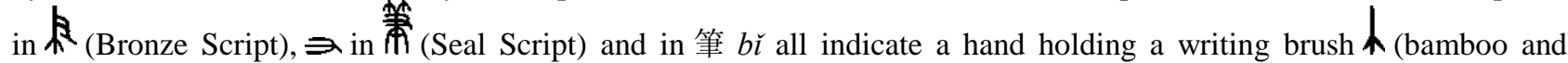
animal air). However, when one hand is holding anything other than a "writing" brush, its indicator will not appear in

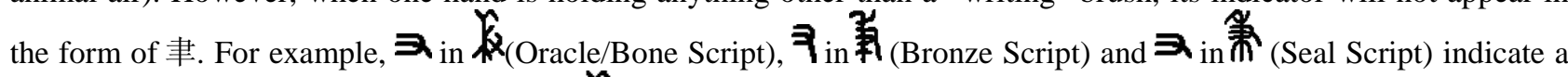
hand grasping one piece of rice seedling $\mathfrak{W}$; the grasping hand and the grasped object are combined and finally transformed into 秉 bing (Shuo Wen Jie Zi and guoxuedashi.com, 2020). 秉 bing cannot be found under the radical 聿 but under the radical J. This way of compiling radicals in a dictionary serves as an example of marginalization for a non-radical component. More examples are found in 类 (Seal Script, 妻 $q \vec{\imath}$ ) with a hand holding the hair of his bride

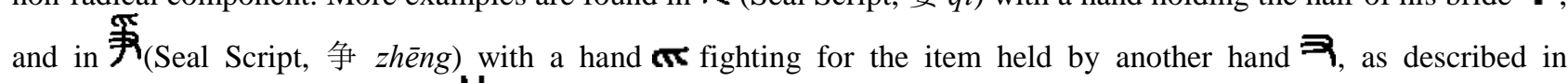

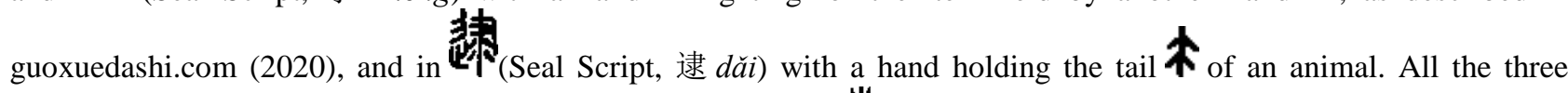

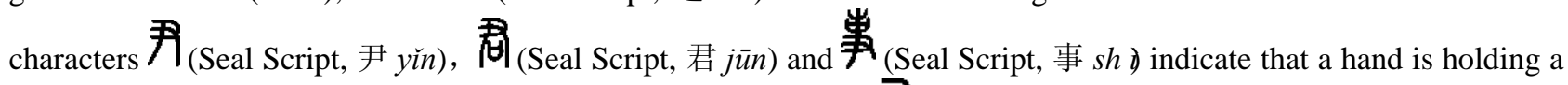
sceptre (guoxuedashi.com, 2020). In all the above examples, when $\boldsymbol{\nexists}$ (a hand) is holding anything other than a (writing) brush, its characters will be listed under other radicals instead of 聿 yù. As a result, its indicator for a hand holding anything other than a (writing) brush will become a non-radical component in a character and its indication for such a hand will be compromised in our Chinese character teaching and learning.

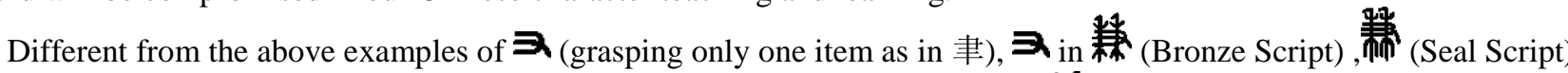
and 兼 jiān indicates one hand grasping two items --- two pieces of rice seedling $\mathbf{k} \mathbf{K}_{\text {at }}$ the same time (guoxuedashi.com, 2020 and Shuo Wen Jie Zi); more examples can be found in 賄(Seal Script, 赚 zhuàn) and 廑 (Seal Script, 廉 lián). When one hand is holding two items $\mathbf{k}$, its joint independent existence into a non-radical component instead of a radical in a dictionary. This marginalized non-radical component will escape our attention and will not be subjected to detailed analysis in our Chinese character teaching and learning. If the indicator for a hand and its connection to holding one item or two items had been brought to our awareness, we might have a better understanding of the meanings of the above characters. 


\section{THIRD TYPE OF NON-RADICAL COMPONENTS}

The non-radical component of the third type has its independent existence both as a character and as a non-radical component instead of being a radical in a character. For example, 丸 wán as a modern Chinese character means "pills”, "pellets" or small ball-shaped items in dictionaries. It has never been listed as a radical in a dictionary. When 丸 wán becomes a non-radical component in a character, it often carries the meaning of "two hands" reaching out to hold an object. However, 丸 wán as a character does not indicate this meaning. 丸 wán as "two hands" only exists as a nonradical component in a character. Therefore, its meaning as "two hands" has been marginalized or predominated by the meaning of 丸 wán as a character which denotes "pills”, "pellets” or small ball-shaped items. For example: the indicator for two hands in the word 执 zhi finds its first version in (Oracle/Bone Script), the second version in 韩

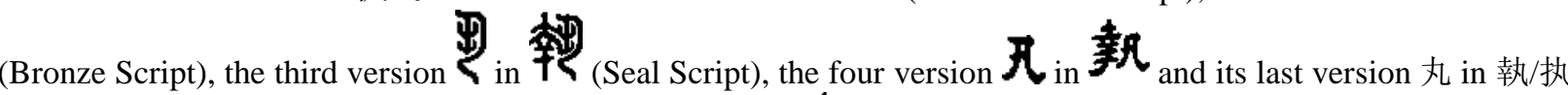
zhi with the two hands bound by a pair of wooden handcuffs $\$$ (chaziwang.com, 2020 and guoxuedashi.com, 2020). More examples can be found in (热 $r e ̀$ ) with the two hands reaching out to hold a torch 1 , and in two hands holding out to plant seedlings and flowers $\Psi$. However, sometimes this sequence is carried out only to $\overrightarrow{\mathcal{H}}$ instead of further to 丸. For example, the indicator for two hands finds the first version in (Oracle/Bone Script),

the second version $\mathbf{S}_{\text {in }}$ (Seal Script) and the last version 凡 in character which denotes "a mold for casting objects" (baike.baidu.com, 2020), a meaning totally different from 凡 as a component. 凡 has never been listed as a radical in a character. 丸 wán as a non-radical component has always experienced the following consistent and visual transformations --through Oracle Bone Script, Bronze Script, Seal Script, Official Script (隶书 Lìsh $\bar{u}$ ) to the modern version 丸 wán. This consistent and visual transformation should be brought to our awareness in our teaching and learning, and its significance in understanding the meaning of these two-hands involved activities should be of great interest and value to the adult learners of Chinese as a second language.

$巴$ bā also belongs to the non-radical component of the third type. It has its independent existence as a character. As a modern character, 巴 bā means "long for; await anxiously; cling to; stick to; the eastern part of Sichuan Province and Chongqing" (Contemporary Chinese Dictionary, 2002, p. 23-4). According to vividict.com, 2020, 巴 bā belongs to "Hand" section. According to jiaguwenzidian, 2020, 巴 $b \bar{a}$ denotes a person with long hands or arms. It is interesting to find that 巴 $b \bar{a}$ is not listed as a radical in a dictionary. However, when 巴 $b \bar{a}$ serves as a non-radical component, especially when 巴 $b \bar{a}$ constitutes the bottom part of a character, it only represents a person. Hence, one can see that when 巴 $b \bar{a}$ exists as a character, its meaning is somewhat different from its meaning when existing as a non-radical component. This difference in meaning will become a challenge to the Chinese character teaching and learning because too much attention will be given to the meaning of a character instead of the meaning of a non-radical component. Therefore, 巴 $b \bar{a}$ as an indicator for a person should be brought back to our attention with the assistance of Oracle/Bone Script, Bronze Script and Seal Script. The notion of 巴 $b \bar{a}$ as an indicator for a person is well-captured in the following

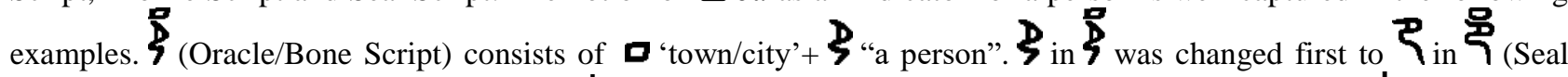
Script) and then to 巴 in 邑 yi 'town/city. 信 was first changed to $\boldsymbol{\xi}_{\text {as in }} \boldsymbol{\mathcal { Z }}_{\text {(Bronze Script) and then as in }}$ (Seal Script) and finally to 巴 in 色 sè. (However, sometimes when $\boldsymbol{\xi}$ as a person constitutes the bottom part of a character, it will undergo the change from $\mathbf{\xi}$, but not finally to 巴, but to

\section{FOURTH TYPE OF NON-RADICAL COMPONENTS}

Any non-radical components which fail to be classified in the above three categories belong to this type. The nonradical component of the fourth type does not have its independent existence as a character but has its independent existence as a non-radical component in a character. At the same time, it has not been deconstructed by its radical. An example of this type can be found in the word 弃 qì. The word 弃 qì is listed under the radical “井” in a dictionary. According to archchinese.com, 2020, the radical “井” indicates "hands joined”. $\succ$ in 弃 qì is a non-radical component of the fourth type because it has never been indexed as a radical in a dictionary and because it does not have its 
independent existence as a character. The mere understanding of the meaning of the radical “井” will not suffice for the whole meaning of the character without the comprehension of the meaning of the non-radical component $\downarrow$. only

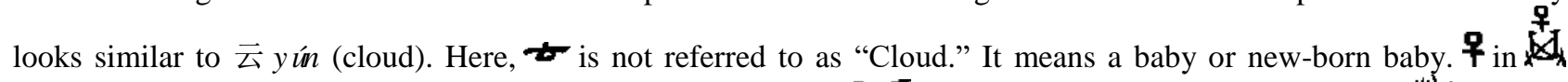
(Oracle/Bone Script) denotes a baby Script). \&े was later changed to examples about $\boldsymbol{\sigma}$ as a baby are found in

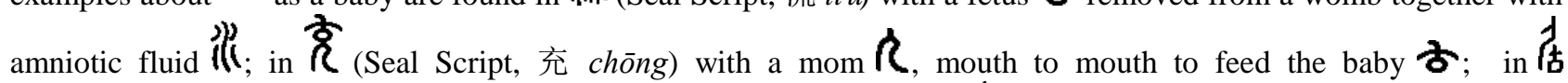
(Oracle/Bone Script) with a woman giving birth to a child 古 as well as in (Seal Script) and hìn indicating a process of both birth $\boldsymbol{\delta}$ and development $\%$.

Therefore, the meaning of a character sometimes cannot be fully deduced without the assistance of non-radical components in a character. However, nowadays Chinese character teaching and learning sometimes rely too exclusively on radicals. If this learning experience persists, we will easily ignore the non-radical components in a character. Therefore, it is crucial to acknowledge the importance of reinstating non-radical components to its well-deserved position in our character teaching and learning.

${ }^{+}$also belongs to the non-radical component of the fourth type. It cannot exist as a character and has never been indexed as a radical. It is a non-radical component which maitains its independent existence in a character. It becomes a marginalized indicator for a hand because the Chinese radical 手/ f has become such a well-known and dominant graphical indicator for a hand in a character that $\mathcal{F}$ becomes less identifiable and even non-identifiable as a hand. However, the Chinese character teaching and learning should be empowered to go beyond the dominant radical such as 手/f. Otherwise, the other overshadowed and sidelined indicators for a hand fail to be identified, and the meanings of many hand-involved characters cannot be clarified and comprehended. For example, the word 有 yǒu is listed under the

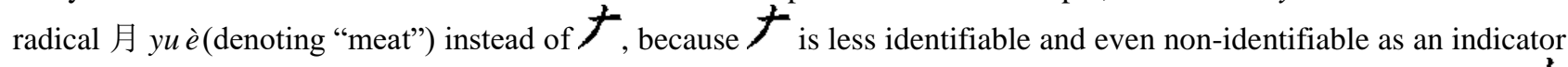
for a hand. The meaning of 有 yǒ u cannot be fully comprehended without the knowledge of the meaning of the hand $\not$.

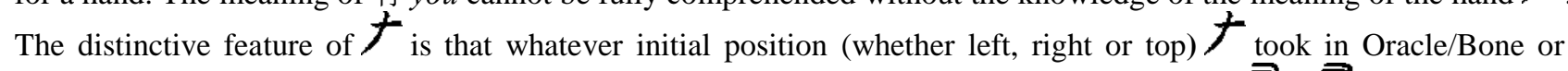
Bronze Script or Seal Script, it would sooner or later constitute the top-left part of a character. in $_{\text {i }}$ (Seal Script, 有 yǒu) first took the top-right position. It later changed its shape from $7_{\text {to }}$ and was relocated to the top-left part of the character 有 yǒu. More examples can be found in (Seal Script, 友 yǒu) and 跑 (Seal Script, 雄 xióng). It is interesting

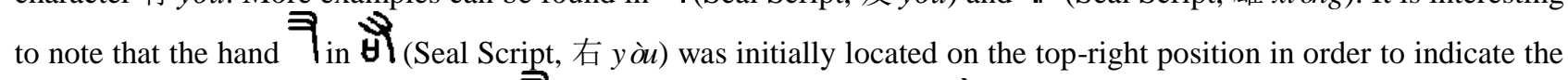

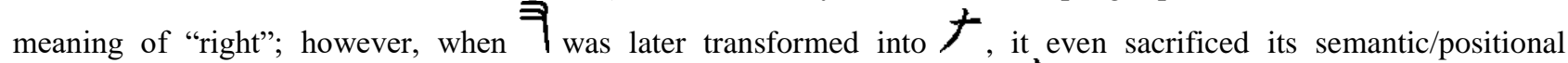
properties for the sake of convenient and consistent positioning. Therefore, $\mathcal{H}_{\text {was relocated to constitute the top-left }}$

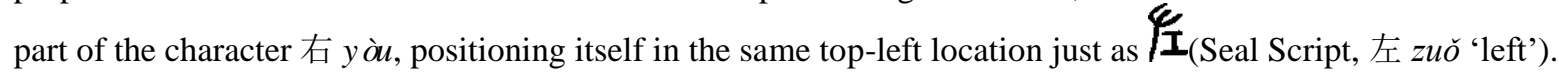

A component becomes "non-radical" mainly because it fails to be chosen as a candidate for a radical according to an 'artificial' standard of indexing and compiling. This failure does not mean that the non-radical component does not convey a meaningful connotation in a character. On the contrary, the non-radical component sometimes plays a crucial role in our full understanding of the Chinese characters. Therefore, more efforts in teaching and learning should be made to go beyond the meaning(s) of a radical in order to have a better knowledge of the marginalized meanings of non-radical components in a character.

\section{GoIng BEYOND THE DOMINANT MEANing(S) OF A RADICAL}

A good knowledge of the dominant meaning(s) of a radical does not suffice now to meet the demand of advanced adult learners of Chinese as a second language. Chinese character teaching and learning should go beyond the dominant meaning(s) of a radical and reach for both the marginalized meanings of marginalized radicals and the marginalized meaning(s) of non-radical components. Chinese character teaching should not be only satisfied with partial understanding of the meaning of a character, especially only the meaning of a radical. Therefore, the non-radical components in a character become crucial in fully explaining the whole meaning of a character. It is time to foreground the original semantic connection between a marginalized radical and its marginalized meaning as well as between a marginalized non-radical component and its marginalized meaning. This reinstatement sometimes will depend upon the assistance of Oracle/Bone Script, Bronze Script, and Seal Script. More researches on marginalized radicals and non- 
radical components, especially representing a person, hand(s), foot/feet and a mouth in Oracle/Bone Script, Bronze Script, and Seal Script should be conducted due to their high-frequent appearance in a character in order to explore the idea of de-marginalization, to strengthen and/or elaborate the current importance related to the marginalized radicals and non-radical component so that a historical and statistical sketch of these marginalized components will be obtained for our future Chinese character teaching and learning.

The following marginalized radicals and non-radical components are organized according to their placement with respect to the other components in a character such as constituting the top part or middle part or bottom part of a character and according to their postures such as a person in a kneeling, sitting, bending position as well as according to the number of their appearance in one character such as one hand or two hands, one foot or two feet, one person or more than one person. A list of marginalized radicals or non-radical components representing a person or hand(s) or foot/feet or mouth is presented below so that an adult learner has a clear idea of the indicators for a person or hand(s) or foot/feet or mouth as well as the number of their appearance in one character such as:

A person constituting the top part of a character:

A person constituting the bottom part of a character: $\boldsymbol{\nearrow}_{->} \boldsymbol{\Omega}_{-}>$U; $\mathbf{S}>\mathbf{P}>$ 巴;

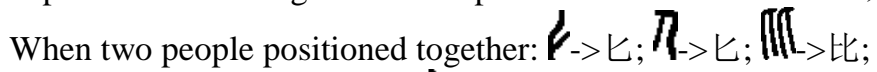

Person in a kneeing position:

Person in a sitting position: $\boldsymbol{\Gamma}_{->} \Gamma_{->}$

Person in bending position: $\mathbf{n}>\boldsymbol{\Upsilon}>$ 勺

One hand constituting the top right part of a character: $\mathbf{X}_{->}$as in 祭;

One hand later constituting the top-left part of a character:

One hand occupying the bottom part of a character sometimes will become “十”: $\boldsymbol{K}_{-}>+$;

One hand with one dot: $\boldsymbol{+}_{+}=$寸;

One hand grasping one item: $\mathbf{Z}->\mathbf{3} ; \mathbf{\Xi}->\mathbf{\Xi}$;

One hand $\mathbf{\nexists}$ grasping two items $\mathbf{*} \mathbf{x}$ as in 兼;

Two hands facing each other will be reduced to one hand grasping one item: $\mathbf{F}$ |- $\mathbf{3}$;

Two hands facing each other like a rib cage: $\boldsymbol{\varepsilon} \mathbf{y}>\boldsymbol{\theta}>\square$;

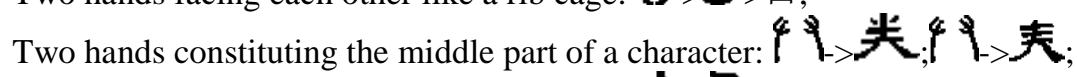

Two hands reaching out or holding out:

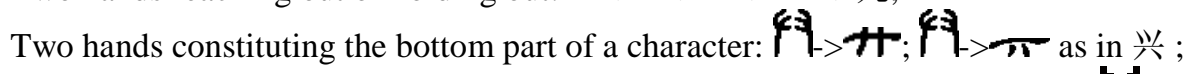

Three hands/four hands/five hands: three hands $\left(\boldsymbol{\Psi}_{+} \rightarrow \mathcal{Z}\right)$ as in 拳; four hands 举.

A mouth constituting the top part of a character: A (inverted mouth); A-> A;

A mouth at the bottom of a character undergoing a change from $\boldsymbol{\nabla}$ to and then to 日;

A foot constituting the top part or the bottom part of a character: $\boldsymbol{\forall ; \mathbf { A } _ { - } > \text { 女; }}$

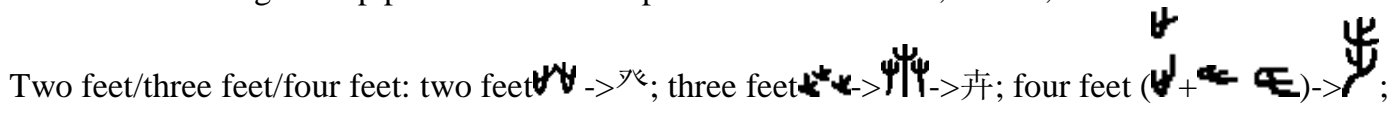

The above images had undergone a change in shape from Oracle/Bone Script to Bronze Script, to Seal Script and finally to the standardised form in modern age:

The significance of the marginalized radicals and the marginalized non-radical components in our character teaching and learning should be reinstated so that Chinese character teaching will become a fun-generating process. This process depends on a full understanding of the meaning of each component in a character, and sometimes this understanding will depend upon the assistance of Oracle/Bone Script, Bronze Script, and Seal Script. A de-marginalizing teaching and learning strategy and a historical story telling approach will make Chinese character teaching and learning much more fun than we expected.

\section{REFERENCES}

[1] Arch Chinese, online. Retrieved on February 3, 2020 from https://www.archchinese.com/arch_chinese_radicals.html

[2] Băidù băikē (Baidu Encyclopedia). Retrieved on Feb 4, 2020 from https://baike.baidu.com/item/\%E7\%AB\%A5/55797; https://baike.baidu.com/item/\%E5\%87\%A1/4520049.

[3] Chá zì wăng. (Character Searching Network). Retrieved on February 7, 2020 from 
http://qiyuan.chaziwang.com/etymology-15675.html;http://qiyuan.chaziwang.com/etymology-5096.html; http://qiyuan.chaziwang.com/etymology-19373.html;http://qiyuan.chaziwang.com/etymology-5001.html; http://qiyuan.chaziwang.com/etymology-138.html;http://qiyuan.chaziwang.com/etymology-840.html; http://qiyuan.chaziwang.com/etymology-13230.html; http://qiyuan.chaziwang.com/etymology-19393.html;

[4] Guóxué dàshī (Master of Chinese Studies). Retrieved on February 10, http://m.guoxuedashi.com/xiangxingzi/850cw/; http://m.guoxuedashi.com/xiangxingzi/294dt/; http://m.guoxuedashi.com/xiangxingzi/834jx/;http://m.guoxuedashi.com/xiangxingzi/1426nd/; http://m.guoxuedashi.com/xiangxingzi/1071jq//http://m.guoxuedashi.com/xiangxingzi/1096mx/; http://m.guoxuedashi.com/xiangxingzi/466ex/;http://m.guoxuedashi.com/xiangxingzi/851ry/; http://m.guoxuedashi.com/xiangxingzi/967ee/;http://m.guoxuedashi.com/xiangxingzi/1082no/; http://m.guoxuedashi.com/xiangxingzi/1056se/;http://m.guoxuedashi.com/xiangxingzi/393op/; http://m.guoxuedashi.com/xiangxingzi/340nl/;http://m.guoxuedashi.com/xiangxingzi/429kv/; http://m.guoxuedashi.com/xiangxingzi/429kv/;http://m.guoxuedashi.com/xiangxingzi/480cd/; http://www.guoxuedashi.com/xiangxingzi/99df/;http://m.guoxuedashi.com/xiangxingzi/76lz/; http://www.guoxuedashi.com/xiangxingzi/1428ar/;http://www.guoxuedashi.com/xiangxingzi/1293am/; http://m.guoxuedashi.com/xiangxingzi/1436em/;http://www.guoxuedashi.com/xiangxingzi/498qm/; http://m.guoxuedashi.com/xiangxingzi/826ji/;

[5] Wei, Dongya et al. (1999). A Chinese-English Dictionary. Beijing: Foreign Language Teaching And Research Press,

[6] Jiăgŭ mìmă. (Oracle Code). Retrieved on February 13, 2020 from http://www.jiagumima.com/html/jiaguwenzidian_4294.html;http://www.jiagumima.com/html/jiaguwenzidian_4151.html; http://jiagumm.com/html/jiaguwenzidian_3479.html;http://www.jiagumima.com/html/jiaguwenzidian_5727.html; http://www.renlu.net/html/jiaguwenzidian_4513.html;

[7] Choy, Rita Mei-Wah. (1990). Read and Write Chinese. San Francisco: China West Books

[8] Xiàndài hànyǔ cídiăn. (Contemporary Chinese Dictionary). (2002). Beijing: Foreign Language Teaching and Research Press,

[9] Xiàngxíng zìdiăn. (Dictionary of Pictographs). Retrieved on February $12, \quad 2020$ from http://vividict.com/Public/index/page/details/details.html?rid=8971; http://vividict.com/Public/index/page/details/details.html?rid=8971; http://vividict.com/Public/index/page/details/details.html?rid=12322; http://vividict.com/Public/index/page/details/details.html?rid=7834; http://www.vividict.com/Public/index/page/details/details.html?rid=11038; http://vividict.com/Public/index/page/details/details.html?rid=8444; http://vividict.com/Public/index/page/details/details.html?rid=8838; http://vividict.com/Public/index/page/details/details.html?rid=8959; http://vividict.com/Public/index/page/details/details.html?rid=7830; http://vividict.com/Public/index/page/details/details.html?rid=8740; http://vividict.com/Public/index/page/details/details.html?rid=8202

[10] Xu, Shen (about 30-149). (100-121, original copy, 1963). Shuo Wen Jie Zi (Analytical Dictionary of Chinese Characters). Zhonghua Book Company.

[11] Liu, Yuehua \& Yao, Tao-Chung et al. (2009). Integrated Chinese, Level 1, Part 1. Boston: Cheng \& Tsui,

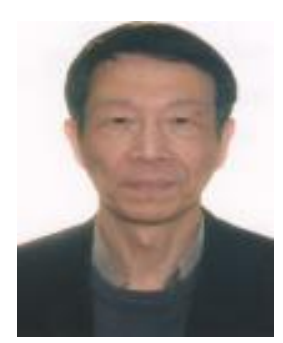

Bianye Li was born in China. He received his Ph.D in Comparative Literature at State University of New York at Binghamton (Binghamton University) in 1998.

He taught Chinese as well as Chinese and Western Literary and Cultural Studies in State of University of New York at Binghamton for two years. Now he is an instructor/professor of Mandarin at George Brown College. He is the translator of the book René Wellek by Martin Bucco and his translation was published by China Social Sciences Publishing House, 1992, Beijing. His book Artificiality in Narrative was published by UMI Dissertation Publishing Services in 1998 online. His article 'A Major Difference between the Formation of English Words and the Formation of Chinese Words in Modern Times' was published by Journal of Language Teaching and Research in 2017.

He is specialized in comparative studies, Mandarin teaching and translation.

Dr. Bianye Li received Teaching Award of Excellence $(2007,2008)$ from Centennial College and Teaching Award of Excellence (2008) from George Brown College. 